\title{
A Critical Study of Electronic Voting Machine (EVM) Utilization in Election Procedure
}

\author{
Dr. A. V. Nikam1, Dr. P. C. Shetiye ${ }^{2}$, Dr. S. D. Bhoite ${ }^{3}$ \\ 1,2,3Associate Professor \\ 1BVDU, Yashwantrao Mohite Institute of Management, Karad, Maharashtra, India \\ ${ }^{2}$ CSE, Government College of Engineering, Aurangabad, Maharashtra, India \\ ${ }^{3}$ Department Mphil. Commerce \& Management Computer Studies, CSIBER, Kolhapur, Maharashtra, India
}

Organised By:

Management Department, Chhatrapati Shahu Institute of Business Education and Research, Kolhapur, Maharashtra

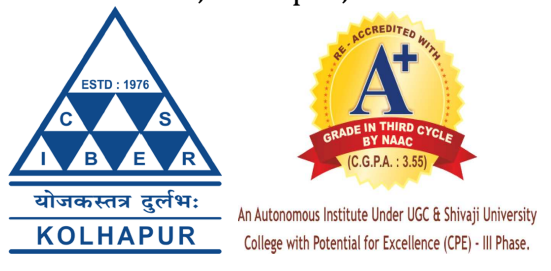

How to cite this paper: Dr. A. V. Nikam Dr. P. C. Shetiye | Dr. S. D. Bhoite "A Critical Study of Electronic Voting Machine (EVM) Utilization in Election Procedure" Published in International Journal of Trend in Scientific Research and Development (ijtsrd), ISSN: 24566470, Special Issue | Fostering Innovation, Integration and Inclusion Through Interdisciplinary Practices in Management, March 2019, pp.1-3, URL: https://www.ijtsrd.c om/papers/ijtsrd23 046.pdf

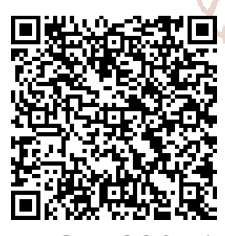

IITSRD23046

\section{ABSTRACT}

We can experience fast and sudden changes in the life of human being due to the information technology (IT). Information technology is used individually as well as in business then how it could be exception for election. In our democracy there are three levels Loksabha, Vidhan Sabha and Sthanik Swarajya Sanshta. Information technology is useful in preparing voters list, proper voting and prediction of which candidate will be winner etc.

Providing the proper services to the voters regarding election for sake of this it has been prepared a software (app) called too voter. Using this app voter can easily search his name in voter list and his election centre etc. It can also be possible to see the expenditure of election through this app. This app is useful to all citizens, voters, election officers, political parties, self service centre, media and political analyst.

The main and important step is actual voting though Electronic Voting Machine (EVM). At the beginning many questions were raised whether literate and illiterate can use this machine properly. It seen that everyone is using this machine. Presently the button called None of the above(NOTA) become part of discussion. Due to EVM following points become possible:

1) Fast counting of voting

2) Accurate counting of voting.

3) Avoidance of misbehavior /misconduct.

Even promotion and dissemination by candidate is possible through information technology. It can possible to get likes about opinions and image of candidate through facebook and twitter.

KEYWORDS: Information Technology (IT), Electronic Voting Machine (EVM), Software, None of the above (NOTA), Media

\section{INTRODUCTION}

It is very critical and important to cast and count votes, the electronic voting is a term used to describe the act of voting using electronic systems

Electronic Voting Machine (EVM) is an electronic device used for recording votes. An Electronic Voting Machine consists of two Units first is Control Unit and second is Balloting Unit that are joined by a 5 meter cable. The candidate names and symbol are programmed in the control unit of EVM. The polling officer in-charge of the control unit will release a ballot instead of issuing a ballot paper by pressing the ballot button on the control unit. This mechanism will enable the voter to cast his vote by pressing the blue button on the balloting unit against the candidate and symbol of his choice.

In Kerala in the year 1982, EVMs were first used in 70-Parur Assembly Constituency. EVMs do not require more electricity. Bharat Electronics Limited/Electronics Corporation of India Limited assembled in built batteries in EVMs and run on it. An EVM being used by Election Commission of India (ECI) can record a maximum of 2,000 votes. 
International Journal of Trend in Scientific Research and Development (IJTSRD) @ www.ijtsrd.com eISSN: 2456-6470

Developed countries like America, Jermany, France etc are mostly use electronic voting machines to count the votes during the general elections. However, with these electronic voting machines there are several controversies are associated. Previously, vote counting was done by paper ballot but with the advancement in technology, electronic voting machines came into the picture.

\section{Objectives of the paper}

The main objectives of the paper are as under:

1. To find merits and demerits of the Electronic voting machine utilization in election procedure.

2. To suggest an algorithm to improve overall procedure of election using electronic voting machine.

There are several merits and demerits associated with the Electronic voting machines.

\section{Merits of electronic voting machines}

1. There are no external communication paths hence it is difficult for the hackers to hack the machine and tamper the count numbers, in most of the advanced version of electronic voting machines.

2. Electronic voting machines with touch base screen are proven to be advantageous for the physically challenged people. In a paper ballot, these physically challenged people were not able to cast their votes in private. However, with the new EVM in place, even handicapped people can use their right to vote in private.

3. Electronic voting machines are cost effective and economical. In the paper ballot, the amount of raw material used is higher. It directly impacts the environment as paper ballot uses papers to cast votes. However, the cost associated with holding elections with EVMs is considered to be negligible.

4. One of the advantages of the electronic voting machine is to save the time. EVM machines can cast and count the votes within very less time.

5. Bogus voting can be avoided through electronic voting machines hence are quite effective against the bogus votes. Electronic voting machines are programmed to capture a maximum of five votes in a minute, due to which a single vote cannot cast fake votes. In advanced electronic voting machines, a sound of beep comes after one casts their vote which lets the officer on duty know that the vote has been cast by an individual.

6. Electronic voting machines are designed in a way that they keep a track of number and details of votes recorded. The election commission can even save the data for a longer period of time which might be helpful for referencing in future.

7. Electronic voting machines are easier to carry and transport from one place to another without any hassle. One single machine can record several votes captured through that machine.

Few electronic voting machines also come with a voice support to assist the visually impaired voter. In such cases, the visually challenged person can cast their vote without any problem.

8. One can see all the symbols and names in electronic voting machines of the candidates together which makes it easier for the voter to choose among the many and cast their votes.

\section{Demerits of electronic voting machines}

Along with the advantages, electronic voting machines are also famous for its misuse. There have been cases when people have accused a particular part of EVM tampering.

1. With recent elections in the United States, many software programmers have claimed that the electronic voting machines are vulnerable to malicious programming and if it gets affected then any hacker can hack the machine and can tamper the vote counts easily.

2. The touch base screen is not efficient enough to capture the vote accurately for many physically challenged people as they have complained that. Therefore sometimes it leads to the voter ending up voting for someone else unintentionally.

3. Although it takes the time to count votes that were captured using paper ballot but people fully trust the process as high technology are also vulnerable to hackers attack.

4. The electronic voting machines which were used during the elections are susceptible to damage which will result in loss of data. Therefore biggest change with technology is that no matter how much data it records but a single virus can destroy the entire data storage.

5. The highly humid area and those areas which receive frequent rainfall are not suitable for casting votes using electronic voting machines. As machines are prone to damage due to high humidity level thus usage of electronic voting machines are not advisable in such areas.

6. Most of the electronic voting machines used in the country were foreign manufactured, which means the secret codes that control the electronic voting machines are in foreign hands and they can be used to influence the election results.

7. Fake display units could be installed in the electronic voting machines which would show manipulated numbers but originally fake votes could be generated from the back end. This process does not need any hacker to hack the software. Such fake display units are easily available in the market.

8. Most of the electronic voting machines used in the country do not have any mechanism by which the voter can verify their identity before casting the vote due to which fake voters can cast numerous fake votes.

9. The electronic voting machines also do not generate a slip confirm the candidate one voted post pressing the button. In these cases, it is very easy for a criminal or a hacker to manipulate the votes. If the machines would generate such slips, then people could verify if the number of votes captured via EVMs was in line with the details on slips received by the voter.

10. Tampering of electronic voting machines can be possible during its manufacturing and in such cases, it does not even require any hacker or malware to manipulate the actual voting.

Now going through the merits and demerits one can decide whether electronic voting machines are useful or not.

Researcher has suggested an algorithm for conducting the proper voting as under:

1. Regular survey should be done properly so as register new voters those who have completed 18 years of age. 
International Journal of Trend in Scientific Research and Development (IJTSRD) @ www.ijtsrd.com eISSN: 2456-6470

2. Motivations to the voters by doing advertisement so that maximum number of number of voters can participate in doing voting.

3. Awareness campaign regarding how voting can be done through EVM and what documents are required at the time of voting that should be announced well in advance.

4. Advanced and secure electronic voting machines should be used.

5. When voter arrive for voting, strict checking and verification of original documents ieadhar card, voting card etc. must be done and all voting can be captured in cc camera.

6. Proper voting procedure must be followed ie checking of name, election centre and remark of voting on finger etc of voter must be done.

7. After carefully completion of voting procedure EVM should kept at proper place with all security measures.

8. Accurate results must be counted and results can be announced and displayed so as to remain transference from the process.

\section{Conclusion}

It is concluded that voting through electronic voting machine is need of time as all developed countries are making use of it. Researchers have been suggested an algorithm and are of opined that if suggested algorithm is strictly followed then there will not be any error in electronic voting procedure.

\section{References:}

[1] https://www.worldblaze.in/advantages-disadvantagesof-electronic-voting-machines-evm/ dated 5/10/2018.

[2] 'Dr. Deepak Shikarpur', 'Lokmat Newspaper', 'Election and Information Technology', 'Page no. 6', 'dated 7/11/2018'.

[3] https://eci.nic.in/eci_main1/evm.aspx dated 10/10/2018.

Copyright (C) 2019 by author(s) and International Journal of Trend in Scientific Research and Development

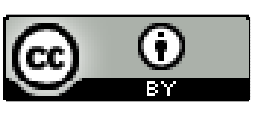
Journal. This is an Open Access article distributed under the terms of the Creative Commons Attribution License (CC BY 4.0) (http://creativecommons.org/licenses/by/4.0)

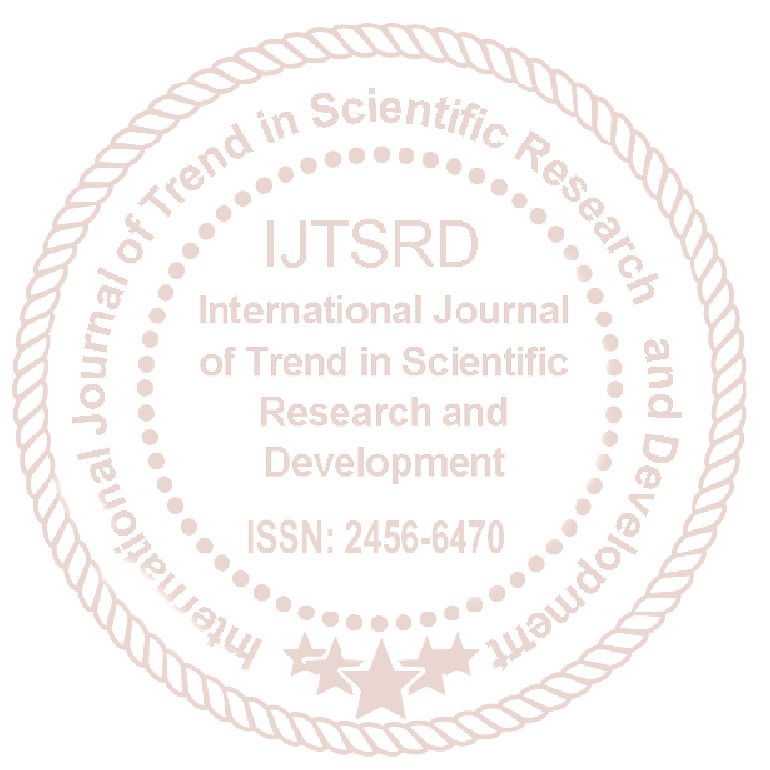

